\title{
Die WLB auf der Landesgartenschau 2016 in Öhringen
}

Die WLB vertritt 2016 zum sechsten Mal das Ministerium für Wissenschaft, Forschung und Kunst Baden-Württemberg auf einer Landesgartenschau. Sie zeigt vom 25. Mai bis 5. Juni in Öhringen einen Ausschnitt der Ausstellung "Haute Couture für Bücher - Einbandkunst in der Württembergischen Landesbibliothek" im Treffpunkt Baden-Württemberg (TBW), der im repräsentativen Hoftheater an der Uhlandstraße gelegen ist. Zusammen mit Frau Mischler vom TBW und einem Repräsentanten der Stadt Öhringen wird Herr Dr. Kowark die Ausstellung am Mittwoch, 25. Mai um 14 Uhr eröffnen, anschließend gibt es einen Stehempfang. Karl Albrecht Fischer, Piano, und Markus Bodenseh, Bass, übernehmen die musikalische Umrahmung.

Angedacht sind folgende Bausteine: Stelen, an denen die Besucher Informationen über die Geschichte und Arbeit der WLB erhalten sowie Einblicke in

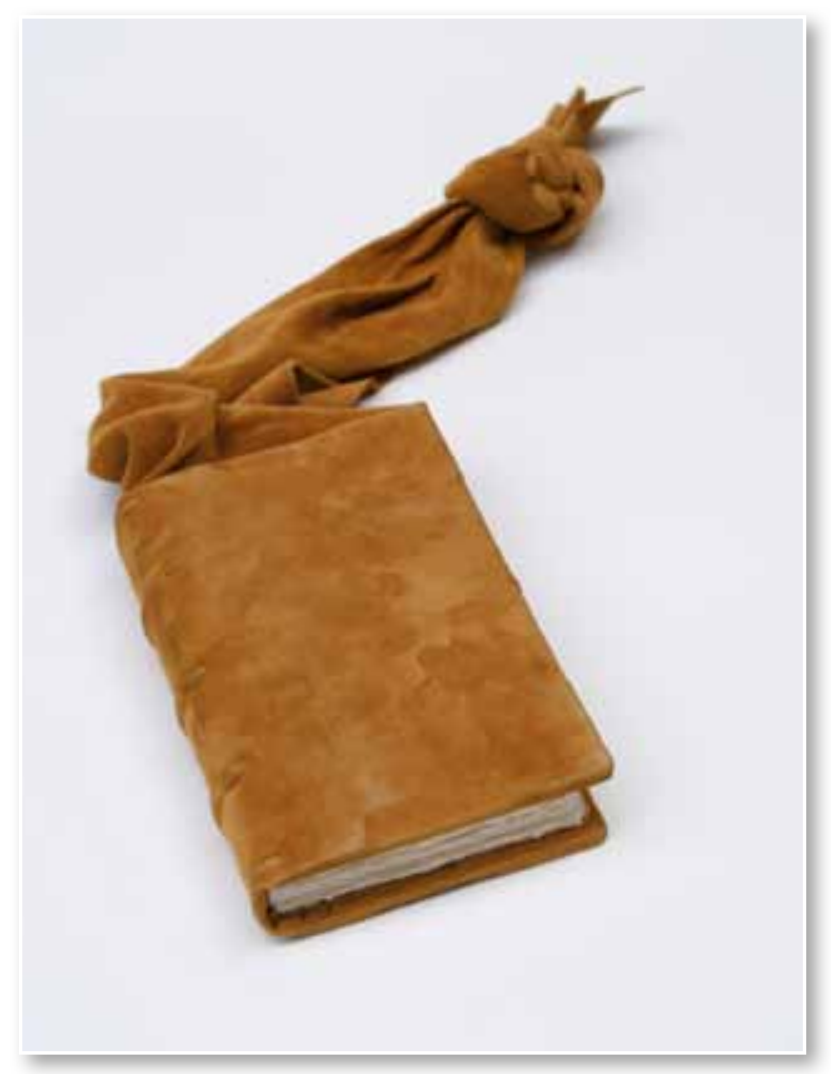

Beutelbuch von Simone Püttmann die Bestandserhaltung, Restaurierung und Notfallvorsorge gewinnen können. An Stelltafeln und in Tischvitrinen werden die Materialien und Techniken historischer Einbände vorgestellt, zwei berühmte Carl-Eugen-Einbände gezeigt, zeitgenössisches Einbandmaterial wie Acrylglas präsentiert sowie Werkzeuge und Instrumente für die Buchbinderei und Restaurierung dargeboten. Drei Standvitrinen enthalten Einbände der Familie Frölich, von Erich Aurich, Gotthilf Kurz, Rudolf Schiller, Heilgart Umfrid, Horst Pichl, Katja Liebig, und Simone Püttman. Während der gesamten Ausstellungszeit sind zwischen 11.30 bis 16 Uhr Aktionen mit Mitarbeitern der WLB, Meistern der Einbandkunst und Restauratoren, die mit der WLB lange Jahre verbunden sind, geplant. Weitere Informationen stehen zeitnah auf der Website der WLB.

Vera Trost

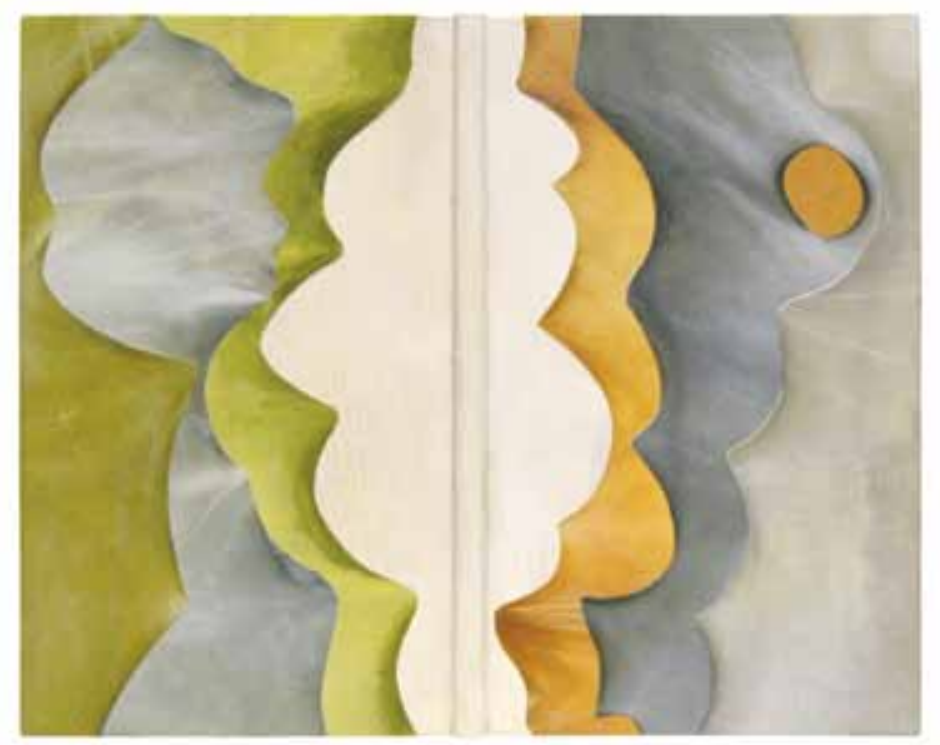

Einband von Michel Frölich 